\title{
COMPARISON OF MECHANICAL PROPERTIES OF NORMAL AND FIBRE REINFORCED
}

\author{
Concrete (Grade M15)
}

\author{
Sagar Bista ${ }^{1}$, Sagar Airee ${ }^{2}$, Shikshya Dhital ${ }^{3}$, Srijan Poudel ${ }^{4}$, Sujan Neupane ${ }^{5}$ \\ 1,2,3,4,5 Department of Civil Engineering, Advanced College of Engineering and Management, Kupondole, Lalitpur
}

\begin{abstract}
Concrete is weak in tension, hence some measures must be adopted to overcome this deficiency as well as to enhance physical and other mechanical properties but in more convenient and economical method. Through many research from the past, it has been observed that addition of different types of fibres has been more effective for this purpose. This report presents the work undertaken to study the effect of steel and hay fibre on normal cement concrete of M-15 Grade on the basis of its mechanical properties which include compressive and tensile strength test and slump test as well. Although hay fibres are abundantly available in Nepal, no research have been popularly conducted here regarding the use of hay fibres in concrete and the changes brought by it on concrete's mechanical properties. Experiments were conducted on concrete cubes and cylinders of standard sizes with addition of various percentages of steel and hay fibres i.e. $0.5 \%, 1 \%$ and $1.5 \%$ by weight of cement and results were compared with those of normal cement concrete of M-15 Grade. For each percentage of steel and hay fibre added in concrete, six cubes and six cylinders were tested for their respective mechanical properties at curing periods of 14 and 28 days. The results obtained show us that the optimum content of fibre to be added to M-15 grade of concrete is $0.5 \%$ steel fibre for compression and $0.5 \%$ hay fibre content for tension by weight of cement. Also, addition of steel and hay fibres enhanced the binding properties, micro cracking control and imparted ductility.

In addition to this, two residential buildings were modeled in SAP software, one with normal concrete and other with concrete containing $0.5 \%$ steel fibre. Difference in reinforcement requirements in each building was computed from SAP analysis and it was found that $489.736 \mathrm{Kg}$ of reinforcement could be substituted by $158.036 \mathrm{~kg}$ of steel fibres and decrease in materials cost of building with $0.5 \%$ steel fibre reinforced concrete was found to be Rs. 32,100 .
\end{abstract}

\section{INTRODUCTION}

\section{FIBRE}

- $\quad$ Fibre is a small piece of reinforcing material possessing certain characteristics properties.

- The fibre is often described by a convenient parameter called aspect ratio.

- The aspect ratio of the fibre is the ratio of its length to its diameter.

- $\quad$ Typical aspect ratio ranges from 30 to 150 .

- $\quad$ Volume percent of fibre used $\left(\mathrm{V}_{\mathrm{f}}=0.1\right.$ to $\left.3 \%\right)$

- $\quad$ Fibers include steel fibers, glass fibers, synthetic fibers and natural fibers.

- Fibre reinforced concrete (FRC) may be defined as a composite materials made with Portland cement, aggregate, and incorporating discrete discontinuous fibres which are uniformly distributed and randomly oriented.

- It resists cracking and crack propagation. The transformation from a brittle to a ductile type of material would increase substantially the energy absorption characteristics of the fibre composite and its ability to withstand repeatedly applied, shock or impact loading.

- Within these different fibers, the character of fiber reinforced concrete changes with varying concrete ,fiber materials, geometries, distribution, orientation and densities.

- The role of randomly distributed discontinuous fibres is to bridge across the cracks that develop provides some post- cracking "ductility". If the fibres are sufficiently strong, sufficiently bonded to material, and permit the FRC to carry significant stresses over a relatively large strain capacity in the post-cracking stage. 


\section{WHY STEEL AND HAY FIBRES?}

Steel fibres are most commonly used fibres and are proved to enhance flexural, impact and fatigue strength of concrete. They are widely used for-overlays of roads, airfield pavements, bridge decks. Hay fibres have high tensile strength and are abundantly available in Nepal, mostly the rural areas where maximum numbers of people are involved in agriculture. If they are found to enhance mechanical properties of concrete, it would be more economic and safer to construct building using hay as fibre.

\section{ADVANTAGES OF FIBRE REINFORCED CONCRETE}

a) Fibre reinforced concrete has started finding its place in many areas of civil infrastructure applications especially where the need for repairing, increased durability arises.

b) FRC is used in civil structures where corrosion is to be avoided at the maximum.

c) Fibre reinforced concrete is better suited to minimize cavitation /erosion damage in structures such as sluice-ways, navigational locks and bridge piers where high velocity flows are encountered.

d) A substantial weight saving can be realized using relatively thin FRC sections having the equivalent strength of thicker normal concrete sections.

e) When used in bridges it helps to avoid catastrophic failures. In the quake prone areas, the use of fibre reinforced concrete would certainly minimize the human casualties.

f) Fibres reduce internal forces by blocking microscopic cracks from forming within the concrete.

g) There may be other cheaper ways to increase strength rather than using fibres but use of fibres in concrete has following dominant features:

1) Fibres increase toughness of concrete.

2) They increase strain at peak load.

3) They provide a great deal of energy absorption in post-peak portion of load vs. deflection curve.

\section{DISADVANTAGES OF FIBRE REINFORCED CONCRETE}

The fibres have to be uniformly mixed and spread throughout the concrete mix. At times, this is found to be a difficult process and time consuming. If this limitation has been overcome by new and effective methods of fabrication, fibre reinforced concrete is found to be more adaptable for common concreting works. The process of incorporating fibres into the cement matrix is labor intensive and costlier than the production of the normal concrete. The real advantages gained by the use of FRC overrides this disadvantage.

\section{OBJECTIVE OF RESEARCH}

a) To find out the value of compressive strength and tensile strength of fiber reinforced concrete due to variation in percentage of fibers.

b) To compare these values with the results of tests on mechanical properties (compressive strength, tensile strength, slump value) of samples of conventional concrete.

c) To compare and choose the optimum percentage of fibre (Steel or Hay) contents in concrete structure respect to its compressive and tensile strength.

d) To compare the reinforcement requirement in a residential building using conventional and fibre reinforced concrete obtained from SAP analysis. 


\section{LIMITATIONS OF RESEARCH}

a) Temperature was not taken into consideration during the specimen preparation and testing as well.

b) Length of the fibre was kept approximately constant.

c) Fibres were manually mixed and distributed in a random manner.

d) Fibres used were wastage of steel (scrap) brought from local grill and steel workshop.

\section{EXPERIMENTAL SETUP}

\section{MATERIALS USED}

- Cement:

It is mixture of calcareous, siliceous, aluminous substances and crushing the clinkers of a fine powder. The ordinary Portland cement of 53 Grade is used. The specific gravity of cement is 3.15 . For ordinary Portland cement, the initial setting time is 30 minutes and the final setting time is 600 minutes.

- Fine Aggregate:

The aggregate whose particles pass through sieve of $4.75 \mathrm{~mm}$ is called fine aggregate. The sand used for the experimental program was locally procured and confirmed to grading zone III. The properties of fine aggregates are: Specific gravity -2.65 and Fineness Modulus -1.958

- Coarse Aggregate:

The material whose particles are of size as are retained on I.S. Sieve No. 480 is termed as Coarse Aggregate. The aggregates are made free from dust before using in the concrete. Its specific gravity is 2.74 and fineness modulus is 7.545 .

- Fibres:

Weight of fibers $=0.5 \%, 1 \% \& 1.5 \%$ by weight of cement

\begin{tabular}{|c|c|c|c|c|c|c|}
\hline Type of fibers & \multicolumn{3}{|c|}{ Steel Fibers (scrap steel) } & \multicolumn{3}{c|}{ Hay Fibers (locally available) } \\
\hline Percent of fibers & $0.5 \%$ & $1 \%$ & $1.5 \%$ & $0.5 \%$ & $1 \%$ & $1.5 \%$ \\
\hline Weight of fibers(kg) & 0.095 & 0.19 & 0.285 & 0.095 & 0.19 & 0.285 \\
\hline
\end{tabular}

\begin{tabular}{|c|cc|c|}
\hline Fibers type & \multicolumn{1}{|c|}{ Steel fibers } & Hay fibers \\
& & \\
& $6.7,7$, & \\
& 6.65, & 5 & \\
Length of fibers $(\mathrm{cm}):$ & $6.1,5.5$ & 5 \\
\hline Average length $(\mathrm{cm})$ & 6.4 & $0.07,0.08,0.07,0.09,0.08$ \\
\hline Thickness of fiber $(\mathrm{cm})$ & 0.07 & 0.078 \\
\hline Average thickness $(\mathrm{cm})$ & 0.07 & \\
\hline
\end{tabular}


- Water: Water used during the experimental work was clean tap water free of impurities.

\section{EXPERIMENTAL WORK}

The process of selecting suitable ingredients of concrete and determining their relative amounts with the objective of producing concrete of the required strength, durability, and workability as economically as possible is termed the concrete mix design. In this study, concrete mix was prepared to make concrete of Grade M15. Mix proportion for M15 is 1:2:4 (Cement: Fine aggregate: Coarse aggregate)

\section{Concrete Mix Proportion;}

Cement $=214.68 \mathrm{~kg} / \mathrm{m}^{3}$

Fine Aggregate $=457.62 \mathrm{~kg} / \mathrm{m}^{3}$

Coarse Aggregate $=971.73 \mathrm{~kg} / \mathrm{m}^{3}$

Water Cement ratio $=0.55$

Water $=118.64$ liter $/ \mathrm{m}^{3}$

The steel and hay fibres were added at percent variation of $0.5 \%, 1 \%$ and $1.5 \%$ by weight of cement in M-15 Grade concrete and was compared to normal cement concrete.

\section{PREPARATION AND DETAILS OF TEST SPECIMENS:}

Casting and testing of cubical specimens of size $150 \mathrm{~mm} \times 150 \mathrm{~mm} \times 150 \mathrm{~mm}$ for compressive strength was done as per IS 516:1959 specifications. Whereas casting and testing of cylindrical specimens of size $150 \mathrm{~mm}$ diameter and 300mm length for splitting tensile strength was done as per IS 5816:1999 specifications. Compressive strength test was performed on $150 \mathrm{~mm}$ cubes, tested at 28 days, with their specimen in each case and cured in the water tank completely immersed at ambient temperature until the test age. All the test specimens were demodulated after 24 hours of casting.

\section{METHODOLOGY}

The methodology adopted to compare the mechanical properties between conventional concrete, steel fibre reinforced concrete and hay fibre reinforced concrete is governed by:

\section{i) COMPRESSIVE STRENGTH TEST}

A number of cubical specimen were made using M15 Grade conventional concrete and FRC with varying percentage $(0.5 \%, 1 \%$ and $1.5 \%)$ of different types of fibers (steel and hay). The samples after curing for 14 days and 28 days were loaded with compressive force in a UTM until the failure occurred. The ultimate strength at 28 days indicated the compressive strength of the respective sample. This test was conducted as per IS 516:1959.

Let,

$\mathrm{P}=$ maximum load carried by the cube before the failure $\mathrm{A}=$ area normal to the load

$=$ maximum compressive stress $\left(\mathrm{N} / \mathrm{mm}^{2}\right)$ Therefore,

Cube compressive strength $\left(\mathrm{f}_{\mathrm{ck}}\right)$ in $\mathrm{MPa}$,

$$
\sigma=1
$$


where, $\mathrm{P}=$ Cube compression load in Newtons $(\mathrm{N})$

$150 \times 150=22500 \mathrm{~mm}^{2}$

$\mathrm{A}=$ Area of the side of cube on which load is applied ( i.e.,

\section{ii) TENSILE STRENGTH TEST}

A number of cylindrical specimen were made using M15 Grade conventional concrete and FRC with varying percentage $(0.5 \%, 1 \%$ and $1.5 \%)$ of different types of fibers (steel and hay). The samples after curing for 14 days and 28 days were placed between the two plates of Universal Testing Machine with its axis horizontal. The load was increased until failure occurred by splitting along a vertical diameter. The ultimate strength of 28 days sample indicated the tensile strength of the respective sample. This test was carried out as per IS 5819:1999 specifications. Let,

$\mathrm{P}=$ maximum load carried by the cylinder before the failure $\mathrm{A}=$ area normal to the load

$\sigma \quad=$ maximum tensile stress $\left(\mathrm{N} / \mathrm{mm}^{2}\right)$

$\mathrm{L}=$ length of cylinder specimen $(300 \mathrm{~mm}) \mathrm{D}=$ Diameter of cylinder $(150 \mathrm{~mm})$ Therefore,

$\sigma$

$=(\mathrm{P} / \mathrm{A}) \mathrm{N} / \mathrm{mm}^{2}$

$=\quad 2 \mathrm{P} /() \mathrm{N} / \mathrm{mm}^{2}$

\section{iii) SLUMP TEST}

Concrete slump test is to determine the workability or consistency of concrete mix prepared atthe laboratory or the construction site during the progress of the work. Concrete slump test is carried out from batch to batch to check the uniform quality of concrete during construction. After preparing M15 Grade concrete (for both conventional type and FRC), fresh concrete were poured in clean moulds in four layers, each layers being tamped by standard steel rod $(16 \mathrm{~mm}$ diameter and $0.6 \mathrm{~m} \mathrm{long})$ for 25 times. The cone was lifted slowly and the decrease in the height of the slump formed prior to the lifting was determined in mm. From this, workability was obtained. Only a true slump is of any use in the test. A collapse slump will generally mean thatthe mix is too wet or that it is a high workability mix, for which the slump test is not appropriate. Very dry mixes; having slump $0-25 \mathrm{~mm}$ are used in road making, low workability mixes; having slump 10-40 $\mathrm{mm}$ are used for foundations with light reinforcement, medium workability mixes; 50-90 for normal reinforced concrete placed with vibration, high workability concrete $>100 \mathrm{~mm}$.

\section{SAP ANALYSIS}

A normal residential building (two and a half storey) was modeled in SAP software as shown in figure with size of each component (beam, column, slab, and staircase) as per the thumb rule of NBC (Nepal Building Code) using M15 concrete. After obtaining the results of cube tests, the percentage of fibre (hay or steel) at which maximum compressive strength was obtained was chosen to replace M15 concrete. Another similar building was modeled with same components size using this fibre. Reinforcement requirements in each component were calculated from results of SAP analysis and compared. Total reinforcement needed in each building was separately summed up and the difference in reinforcement requirement due to the replacement of conventional concrete by FRC was calculated. The size of building components used was: 
Columns: $12 " * 12 ”$

Beams: 9"*14"

Slabs: $5 "$

Steel Rebar: Fe500

Concrete $\quad$ : Conventional M15.369 and FRC M18.055

Room Size: $5 m * 5 m$

The loads on the building were taken as:

Live Loads (LL) $\quad=2 \mathrm{KN} / \mathrm{m}^{2}$

Floor Finish $(\mathrm{FF})=1.2 \mathrm{KN} / \mathrm{m}^{2}$

Wall load (WL) $\quad=12 \mathrm{KN} / \mathrm{m}$

\section{RESULTS \& ANALYSIS}

The final average result of the experiment is summarized in the table below:

\begin{tabular}{|l|c|c|c|c|c|c|c|}
\hline $\begin{array}{l}\text { S. } \\
\mathrm{N}\end{array}$ & Concrete type & $\begin{array}{r}\text { \% of } \\
\text { fibre }\end{array}$ & $\begin{array}{r}\text { Slump } \\
(\mathrm{mm})\end{array}$ & \multicolumn{2}{|c|}{28 days average load in } & \multicolumn{2}{|c|}{$\begin{array}{r}\text { 28 days average } \\
\text { strength in }\left(\mathrm{N} / \mathrm{mm}^{2}\right)\end{array}$} \\
\hline & & & & Tension & Compression & Tension & Compression \\
\hline 1 & Normal & 0 & 27 & 96.2 & 345.8 & 1.362 & 15.369 \\
\hline 2 & Steel fibre reinforced & 0.5 & 20 & 101.6 & 406.23 & 1.438 & 18.055 \\
\hline & & 1 & 11 & 85.7 & 350.07 & 1.213 & 15.559 \\
\hline 3 & Hay Fibre reinforced & 0.5 & 14 & 104.6 & 333.43 & 1.547 & 14.819 \\
\hline & & 1 & 13 & 92.37 & 307.03 & 1.307 & 13.646 \\
\hline & & 1.5 & 11 & 78.4 & 274.03 & 1.11 & 12.179 \\
\hline
\end{tabular}




\section{i) Slump Test}

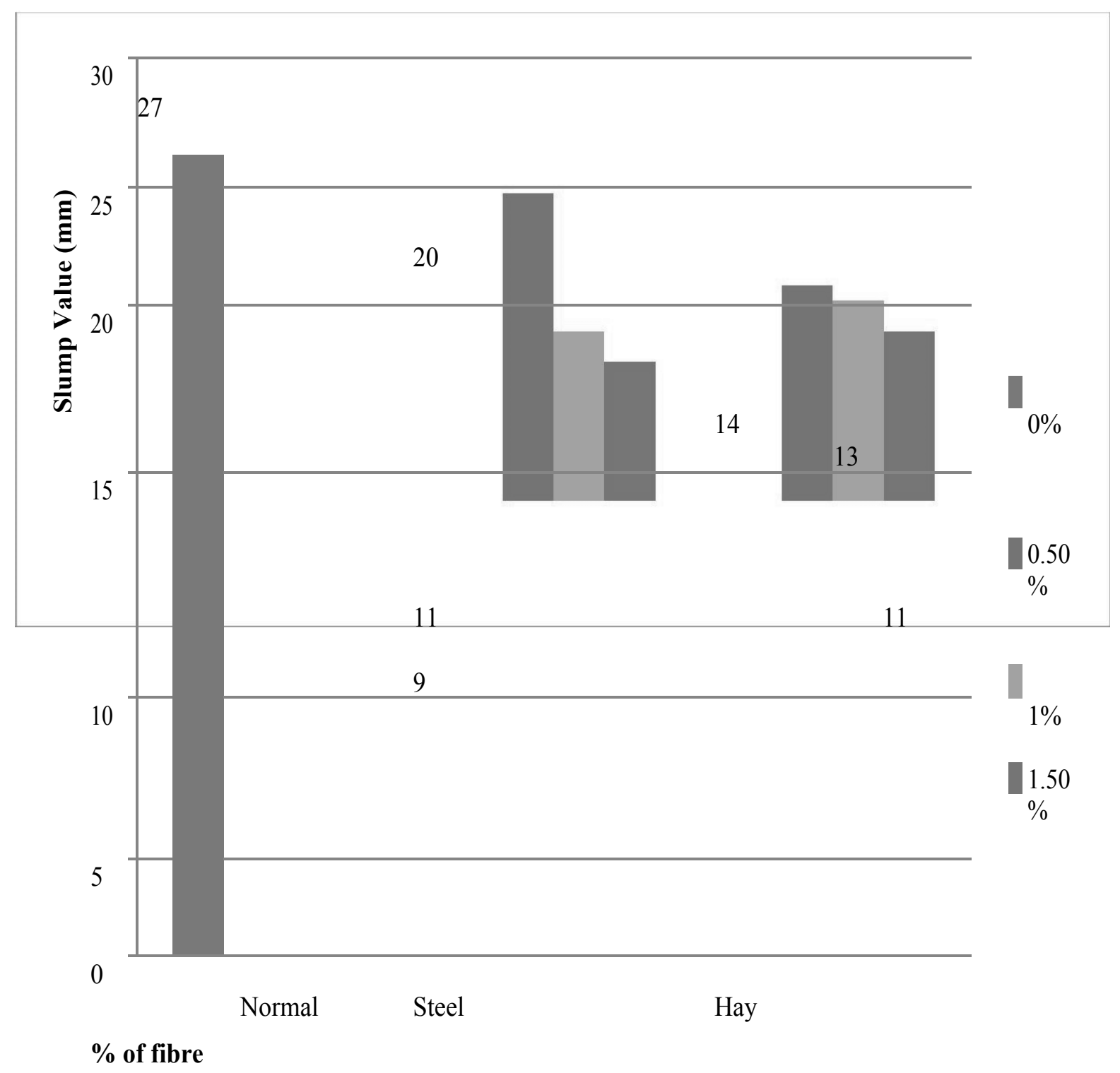


It was observed that the slump value gradually decreased with increase in fibre content. In steel fibre, the slump value reduced by $25.9 \%, 59.3 \%$ and $66.7 \%$ for fibre content of $0.5 \%, 1 \%$ and $1.5 \%$ respectively in comparison to slump value of normal concrete. Similarly in hay fibre, the slump value reduced by $48.2 \%, 51.9 \%$ and $59.3 \%$ for fibre content of $0.5 \%, 1 \%$ and $1.5 \%$ respectively in comparison to slump value of normal concrete.

\section{ii) Compressive Strength Test}

\section{8 days average compressive strength result}

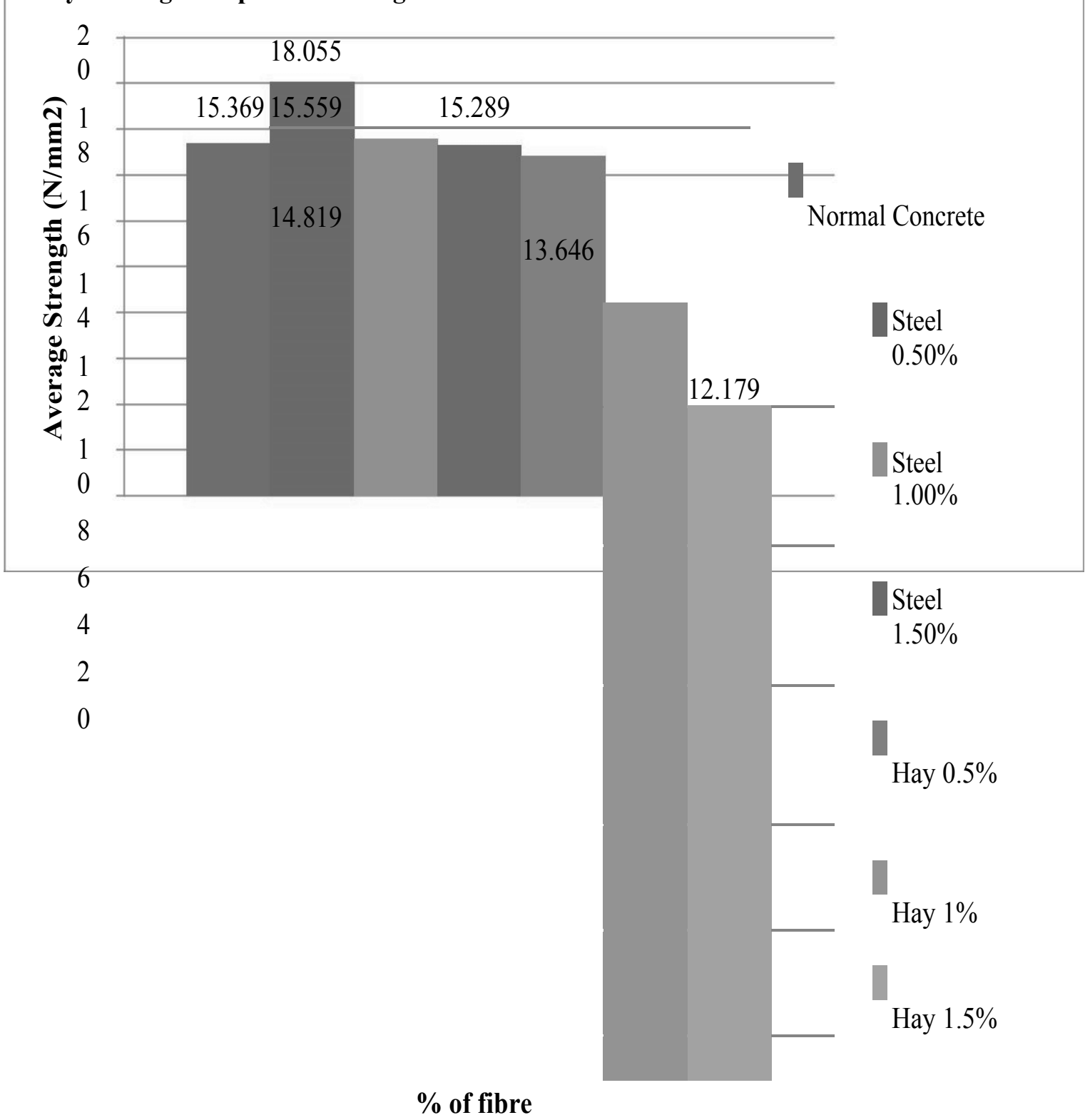

From the test results, it was observed that the 28 days average compressive strength of steel fibre increased by $17.5 \%$ and $1.2 \%$ for fibre content $0.5 \%$ and $1 \%$ respectively while decreased by $0.52 \%$ for fibre content of $1.5 \%$ in comparison to that of normal concrete. 


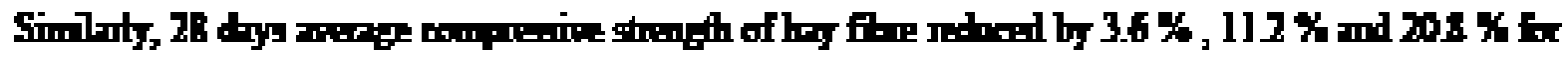

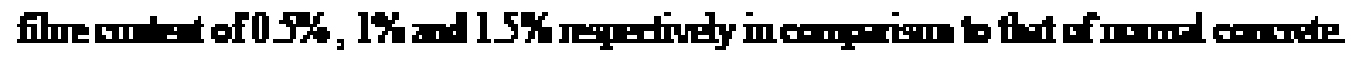

尚 Te.7. Strugeth Tet

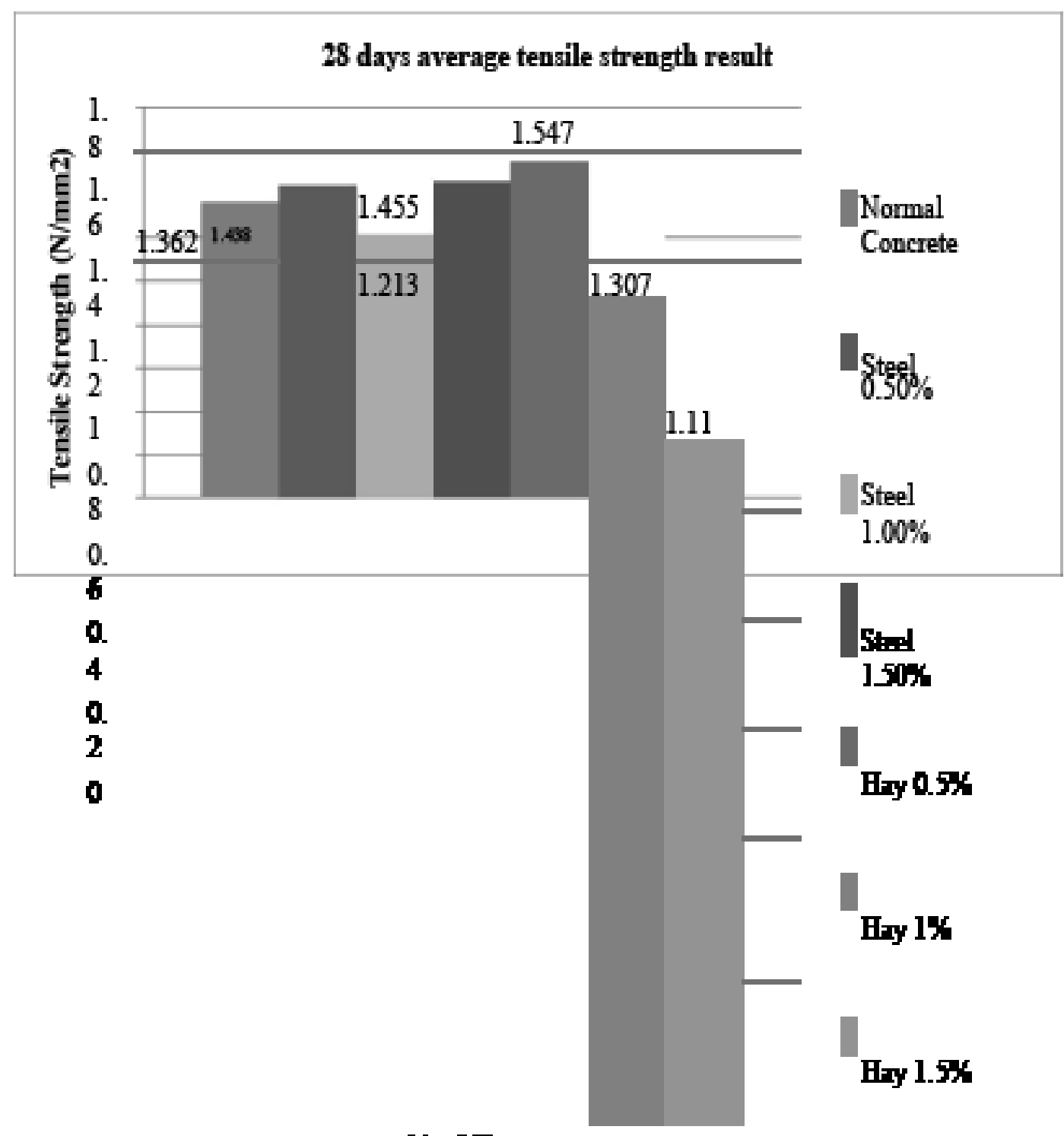

*Afilue

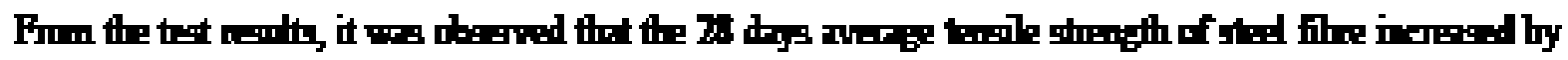

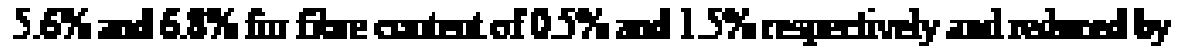




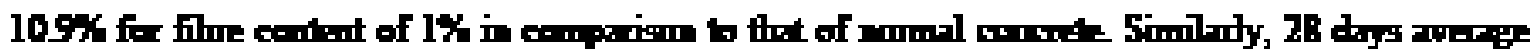

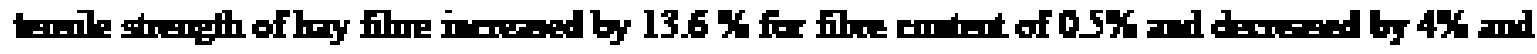

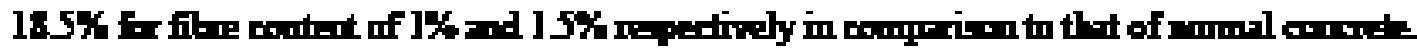

\section{RDINFORCETENT CALCULATION FROM SAP OUTPUT}

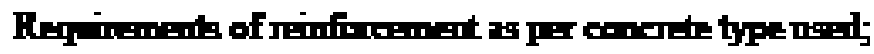

\begin{tabular}{|c|c|c|}
\hline & 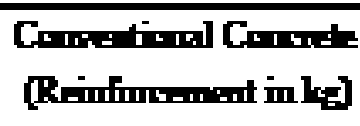 & 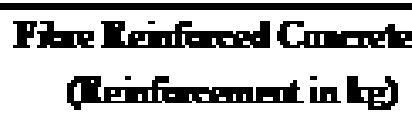 \\
\hline \multicolumn{3}{|l|}{ Betling Compon:antr } \\
\hline Golmings & 245.785 & 2202602 \\
\hline Bemb & 3912.65 & $3 \times 31.115$ \\
\hline 된a & 1735231 & 1720265 \\
\hline Strir & 812959 & 656.12] \\
\hline 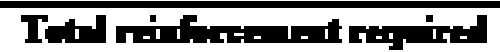 & 891984 & B430.104 \\
\hline
\end{tabular}

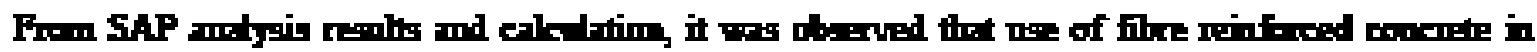

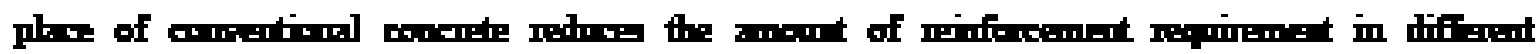

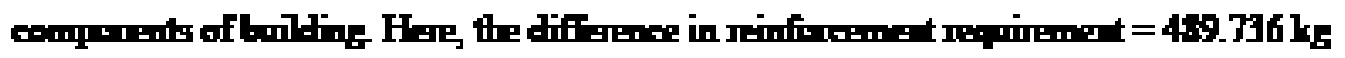

Profit i rein frcement $=$ Rs 35, 261 (Rs 7 parg)

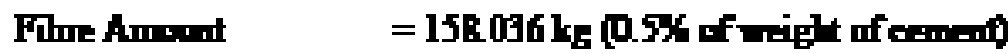

Cust of ated fire $=$ T 3,160.7 (Rs 20 perkg)

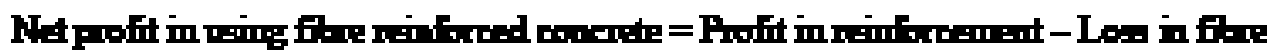

$=R_{2} 32,100$

\section{CONCLUSTON \& RTCOUMTIMATION5}

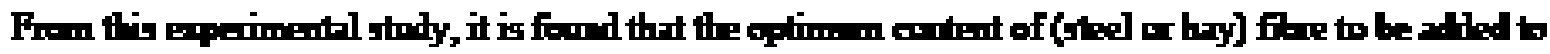

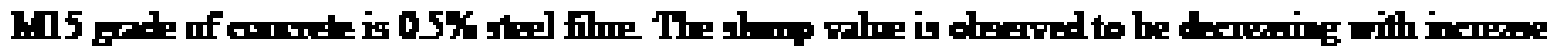
in filke contint of both hry and stal

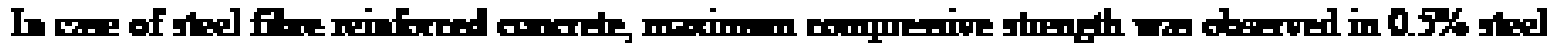

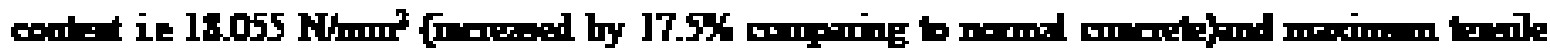

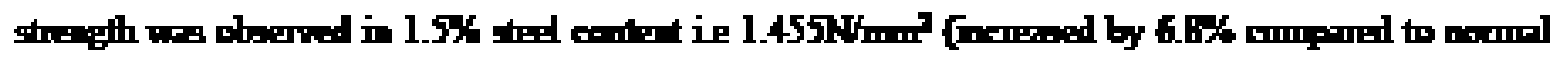
concitis].

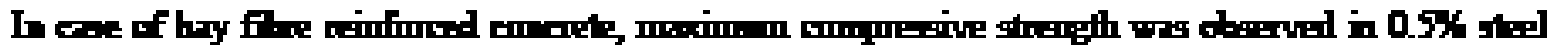

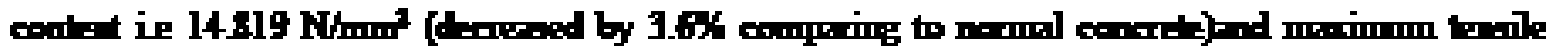

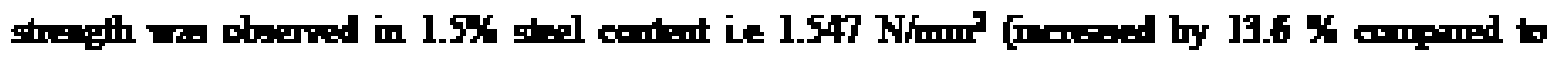
numal conendr). 


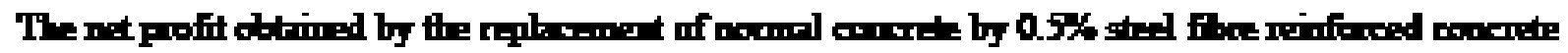

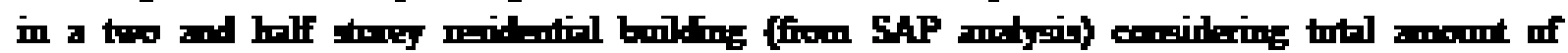

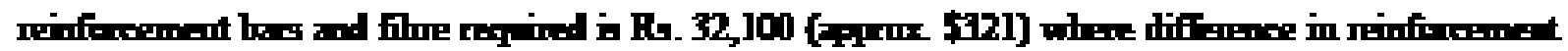

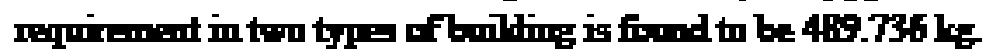

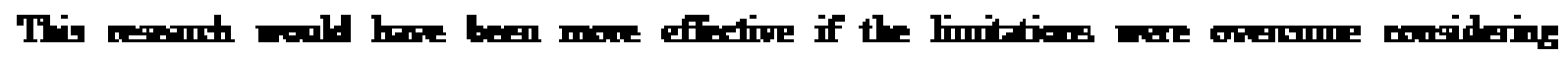

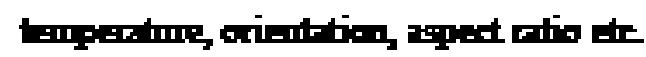

Freblem Finconted

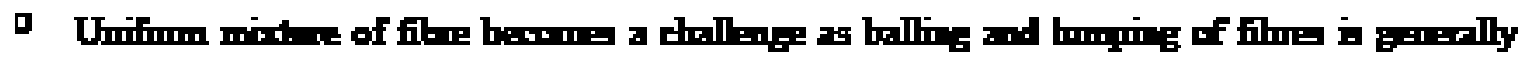

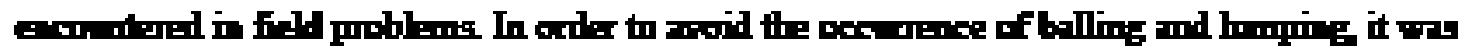

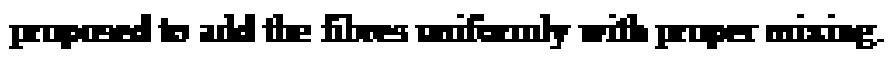

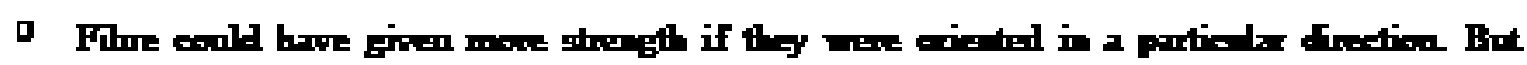

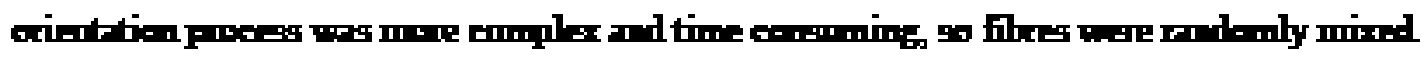

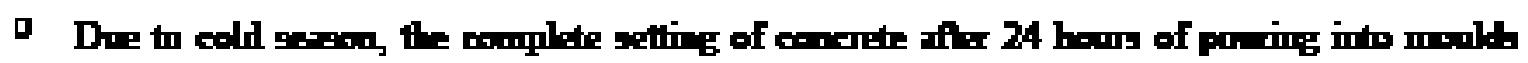
wes not earily acliped

Futre 5oepe

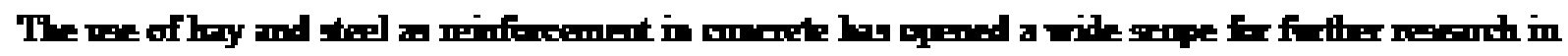
this putioler field They ac:

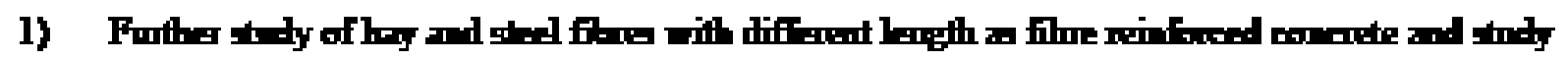

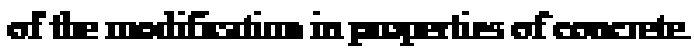

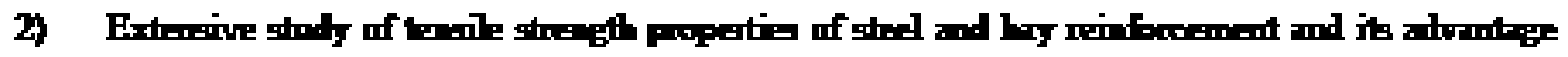
in cmetrotion witks

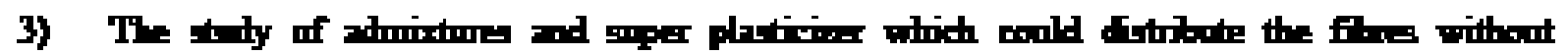
affectimg the pripentiog of coinde

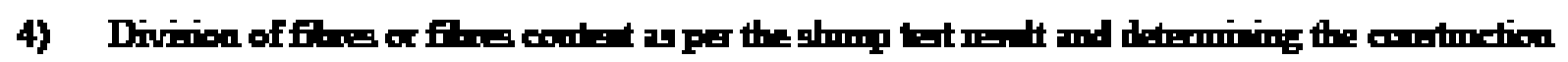

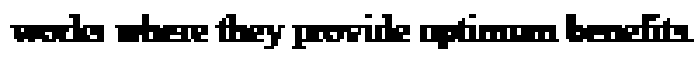

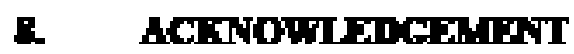

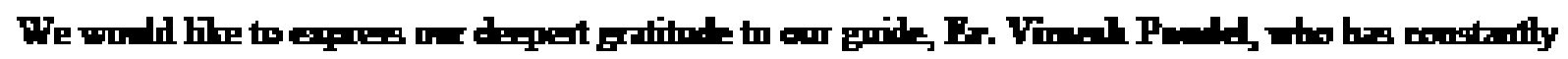

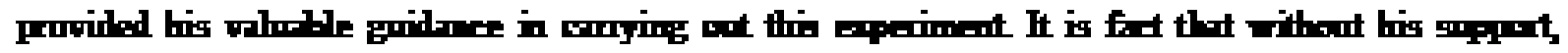

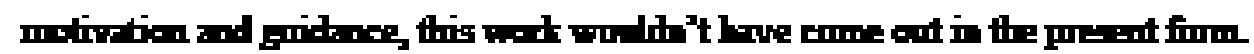

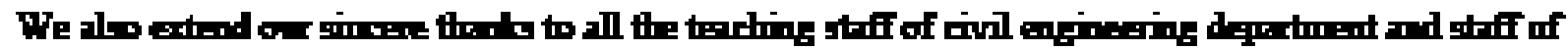

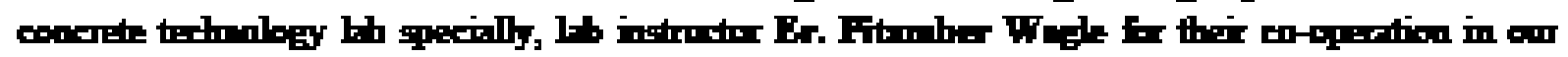

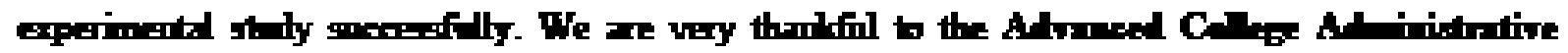

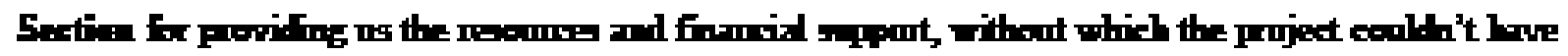
bein innyined to initite

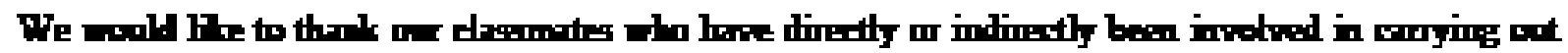

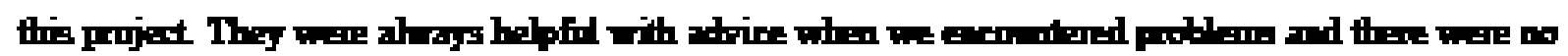
ore to seele ant for help 


\section{REFבस:JNCES}

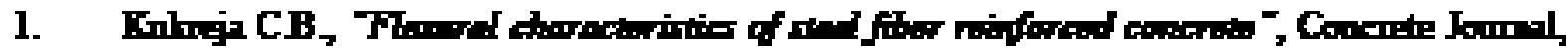
Jub (1980), Fp.]34-18:.

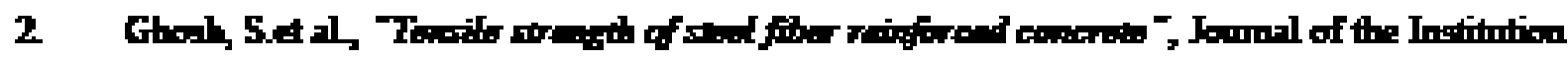

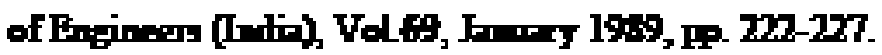

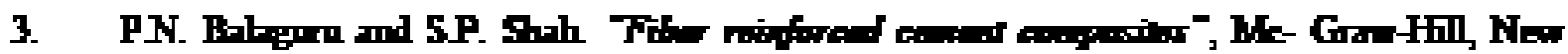
Yat, 1992, Xii, 530-PP.

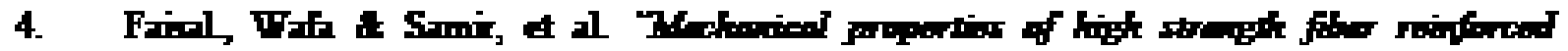

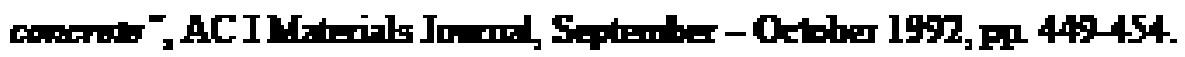

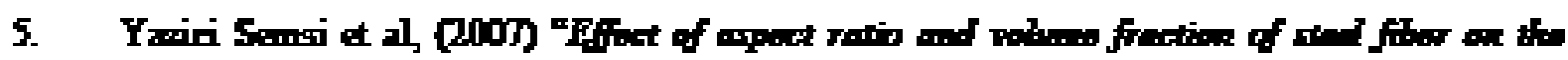

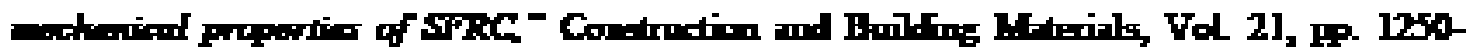
$1253,2007$.

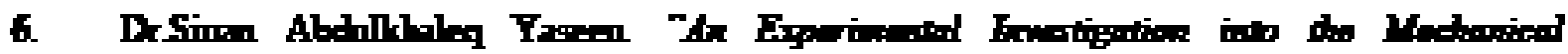

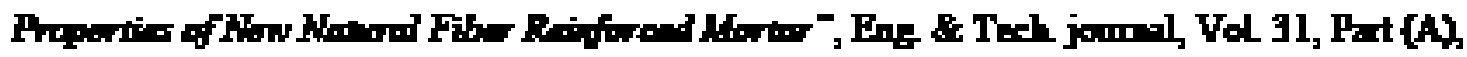
No.10, 2013 .

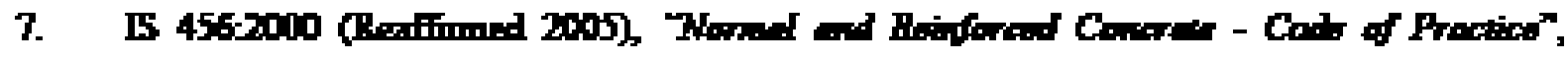

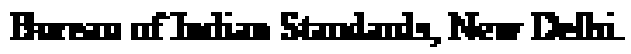

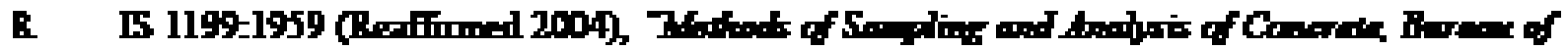

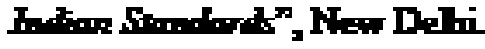

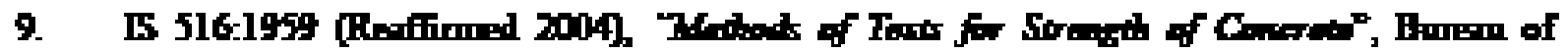
Indian Strater hes, New Delli

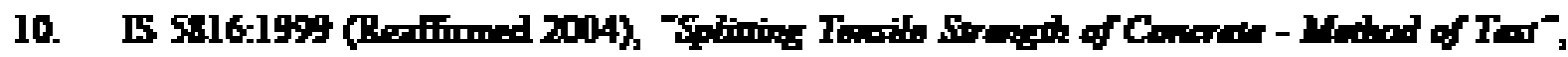

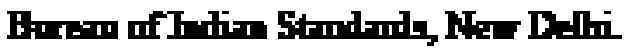

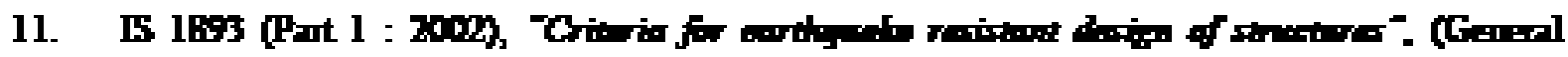
porivime and baldinge) 